\title{
Malnutritional keratitis
}

\section{By C. J. Blumenthal, 28 St. Fames' Road, East London, South Africa}

In this paper I attempt to reassess and stress certain features of the eye condition to which I gave the name malnutritional keratitis.

I have already expressed the view (Blumenthal, 1950), not untinged with doubt, that this entity appeared to be peculiar to the South African Bantu, and resulted directly from a diet unbalanced by an excess of carbohydrate. Although this and my following paper (Blumenthal, 1954) on the subject aroused considerable interest in various quarters of the globe, I have been surprised at the complete absence of any published evidence in support of the suspicion that the condition should occur in other starch-eating and underprivileged peoples living in countries ecologically similar. It is my hope that, under the distinguished patronage of The Nutrition Society, this paper will stimulate (might I say) the necessary response.

In order to spike the guns of the overmeticulous, I would like to state at this juncture that when I first dubbed the condition malnutritional keratitis, I realized that this was, in the strictly pathological sense, a misnomer. The lesion is not inflammatory. It is true that by the time one first sees many of these cases, the underlying primary condition is usually overshadowed by secondary infection, and the attendant inflammation tends to dominate the picture.

The primary corneal phenomenon is essentially one of quiet, painless and visually symptomless liquefaction of the cornea usually at one small circumscribed point. The position is nearly always in the lower half, rarely at the equator, and only very, very seldom in the upper half of the cornea. Although variations in the circumferential position of the lesion can occur, its radial distance from the limbus never varies. In a prolapse of average extent the perforation is always initially a millimetre or so from the corneo-scleral junction, never central or paracentral and never extracorneal; a large and expanding prolapse can, however, on occasion overflow these points or involve the limbus itself ( $\mathrm{Pl}$. $\mathrm{r} a$ ). Most forms of corneal ulceration leading to perforation have clinically a beginning, a middle and a terminal phase. It is not so with the perforation of malnutritional keratitis. That there must be a beginning to the pathological process is something that one must accept. So imperceptible, so rapid, and so insidious must the corneal changes be, that clinically the pre-prolapse stage is never seen. I have been on the alert for this stage for nearly 20 years and have never yet been successful in finding an eye for which one could prophesy that an iris prolapse was about to take place. I may seem to dwell too long on this aspect of the subject, but it appears to me that this process, this rapid lysis or liquefaction, is the core of the mystery, and might well have a bearing on nutritional problems in general.

In the common single prolapse, the pupil assumes a pear shape similar to that of a traumatic prolapse. In the much less common double prolapse the pupil is elliptical. 
In the very rare triple prolapse the pupil is triangular (PI. I $b$ ). I was fortunate to see the last a few months ago. The only other triple prolapse that $I$ have seen in 20 years was so scarred and destroyed by secondary infection that it was impossible to get a clear photograph of it. It would appear that when more than one prolapse occurs in the same eye, the prolapses do not occur simultaneously. The last has already healed before the next appears. Deep corneal infection is rare. I have yet to see a hypopyon develop concomitantly, or for that matter at any stage. The secondary infection I have mentioned is nearly always superficial, and only rarely penetrates deeply in long-standing cases in which the cornea is thinned and seriously devitalized.

I had at first firmly believed these prolapses to be the result of ulceration beginning superficially in the epithelium. I then saw, not without some excitement, my first case of early prolapse covered with what appeared to be a soggy unbroken membrane. This and subsequent examples showed, on tangential abscission and serial section of the prolapse, that this membrane was in fact the unbreached corneal epithelium. In at least one other case a descemetocoele was present. If my interpretation of these clinical and histological observations is correct, it would appear that the initial breakdown occurs in the substantia propria. Connective tissue (i.e. tissue derived from mesoderm) is therefore the vulnerable layer.

A striking feature of the early clean spontaneous iris prolapse is the absence of ciliary irritation. There is no photophobia and no circumcorneal injection. Section of the prolapsed portion shows normal iris, and complete absence of increased vascularity or of cellular infiltration. At the later stage of organization of the margin of the breached cornea, or when secondary infection takes place, signs of ocular irritability can become markedly manifest.

On the assumption that we are dealing with a nutritional problem, one would expect a marasmic, emaciated child. The contrary is usual. Despite the fact that the skin and hair show an absence of healthy sheen and crispness, and the demeanour is one of lethargy and indifference, the podgy and well-fed appearance is striking, albeit deceptive. There are exceptions to every rule, and one does occasionally come across an emaciated infant. Starvation, as regards quantity, is a rarity in the Bantu of South Africa. The pot-belly of the African baby, much-beloved of the picturepostcard sentimentalist, is almost certainly the outcome of a bulky diet of fermentable starch. 'The sensation of repleteness is dependent on a bloating or distension of the stomach and is a habit acquired early by the Bantu, remaining with him all his adult life. A taste for more delicately flavoured foods is rare even in the more educated and westernized Bantu though economic and other opportunities offer. The adult Bantu is habitually capable of consuming prodigious quantities of stamped boiled mealies, white bread, porridge, baked beans and so on. Although he has a strong liking for meat, when obtainable, he achieves satisfaction more by quantity than quality. The picture of gorging almost to the stage of bursting and torpidity at feasts is one to make even the most hardened western stomach quail. As in many primitive peoples, a predilection for green vegetables and fruit is dependent on the ease with which they are obtained. The Bantu are by nature indolent, and as a rule 
make poor gardeners. Despite the well-meaning efforts of mission stations, Government agricultural officers, and others, attempts to inculcate sound gardening and farming practices usually fail. Traditional prejudice, laziness and a child-like laisser-faire have made maize the national staple. Inevitably, in the native reserves, exhaustion and widespread and frightening erosion of the soil have been the result.

The evidence that malnutritional keratitis is a nutritional disease is in my opinion overwhelming. When from the statistics of a large number of case histories I found that the greatest number of acute cases occurs between the ages of 2 and 5 years I was at first puzzled, until it struck me that the African mother suckles her child for as long as $2-3$ years. In every case history it was found that the baby after being weaned was put on a diet of white refined maize meal, unsupplemented by fresh or sour milk, fish, eggs, fruit or vegetables. The response of even badly affected eyes to a wholesome mixed diet (and to no other treatment whatsoever), and in the astonishingly short period of a week to Io days, cannot but impress even the most sceptical. A failure to produce this typical result is nearly always due to concomitant disease, usually tuberculosis. There are many difficulties in the way of dietary experimentation, and I regret that I cannot yet tell which particular factor (or factors) is necessary to forestall this condition. A body of helpers, a large sum of money and special hospital and isolation facilities are the first requirements. Add to this the mysterious variables at work in the individual himself. As an instance of the variable susceptibility of tissues, we have the example of the triple prolapse (Pl. I $b$ ). Why in a systemic condition should one eye suffer three prolapses one after the other, and the fellow eye none? What is the extra insult? What protects some children, and some eyes, and exposes others?

I have dealt at some length with the primary condition-the clean spontaneous prolapse; I would like briefly to add a few more observations. At first when confronted with these prolapses, a sense of surgical propriety caused me to admit and to abscise them, as one would automatically any traumatic prolapse. Experience soon showed the uselessness, nay, the undesirability of interfering with them. The prolapse becomes adherent extraordinarily quickly, and it is virtually impossible to free the iris adequately, and restore the pupil. One is left with the feeling of having achieved nothing, even of having produced more damage. If left alone these prolapses heal very well, leaving a scar, and a misshapen and eccentric pupil, but often an eye with useful vision. Complications such as iritis, sympathetic ophthalmia or cataract do not occur.

In a previous paper (Blumenthal, 1950) I described various clinical types of malnutritional keratitis, e.g. the teat or nipple type, pseudobuphthalmic forms, and various types of corneal scarring. These I came to associate with malnutritional prolapse, by finding them repeatedly in the fellow eye, and by an absence of history pointing to other possible diagnoses, e.g. gonococeal ophthalmia. It seemed to me that a softening and weakening of the cornea at several points inside and adjacent to the limbal ring, but not progressing to actual perforation and prolapse, might well give rise to these forms. 
One form, however, deserves further mention. Sooner or later these eyes are prone to secondary infection. A chronic conjunctival catarrh, no doubt caused by a variety of organisms, eventually leads to a condition very similar to and, I suspect, often misdiagnosed as, trachoma.

I now come to a feature of this disease which I think might, if I am proved right, lead to important discoveries as regards resistance to other diseases, longevity and so on. The state of the prolapse leaves a very typical scar or scars. That this 'trade mark' should disappear in adult years, is in the light of ophthalmic experience inconceivable, and it is not unreasonable that over a period of 20 years one should expect to see a fair number of these old healed eyes in older patients, perhaps presenting themselves for refractive errors, or superimposed injury or other disease. The fact that one does not see them cannot be ascribed to mere chance. Apart from my own search for such cases, I have asked my house surgeons and my out-patient sister (who has worked in my clinic for the last ro or I I years and who knows the condition as well as $I$ do) to be on the alert for cases in this age group. In spite of having seen many hundreds of the 'acute' eyes in the very young, and hundreds of the 'aftermath' cases in adolescents and young adults, the fact remains that these eyes rapidly dwindle numerically, in the 20's and 30's, and to find one after the age of 40 is a rare event indeed. What happens to these people? Two conclusions offer themselves: firstly, that this is a recent disease of the Bantu and, secondly, that people afflicted with malnutritional corneal disease in infancy do not survive the usual disease hazards of early and middle life. Taking the first hypothesis, how is one to judge? As an ardent soil conservationist, I would like to point an accusatory finger at the eroded hillsides of the native reserves. Perhaps $40-50$ years ago there was more nourishment in the soil, more wild fruit, roots and game. But the rural Bantu is, with few exceptions, by nature a child. $\mathrm{He}$ is, as well as being indolent, carefree and happy-go-lucky, very much a creature of habit and tradition, and it would surprise me to learn that the customary, accepted ideas of infant feeding have undergone any radical changes, say, in the last 50-100 years. Maize is the staple food of the Bantu, simple to cook and to keep heated over the fire all day. Cattle are regarded more in the light of hoarded wealth and security, and are seldom slaughtered for food. They are the accepted currency of 'lobola', the price paid by the aspirant groom to the father for the hand of his daughter. Before Union in 1910, there were few records kept of the incidence of disease, and a system of payment of pensions for the blind is only a decade or two old. That ophthalmology is itself a highly specialized subject needs no stressing. One therefore cannot expect much help from older practitioners or medical missionaries in outlying areas, and what records they kept are of little assistance.

When it comes to the second hypothesis, do these people die as the result of some defect or deficiency laid down at an early and vital stage in their childhood years? If, as I have suggested, mesodermal or connective tissues are damaged in the eye, could it not be that analogous tissues are adversely but invisibly affected, throughout the whole body, never completely to recover, however much the nutrition might improve in later years? An interesting speculation (based on this hypothesis) is that 
few of these cases would appear to die of cancer, for the simple reason that they do not attain the cancer age.

I have mentioned elsewhere that not all cases go on to a full perforation or prolapse. Some are left with a corneal scar or scars and one eye may appear to be completely spared. A retinoscopy in such an eye will, however, often betray irregular corneal 'swirls' without any actual opacity, which suggests that some minimal, subclinical damage has been suffered by the corneal lamellae, producing no more than a modicum of irregular astigmatism.

What is the exact value and purpose of connective tissue? As it is perhaps the most important repository of the materials of repair and nutriment, the highway for arteries, nerves and tissue fluids, one would imagine that any permanent damage to its components might at an earlier or a later stage lead to changes in the epithelia and endothelia which it underlies, supports and nourishes.

My thanks are due to previous house surgeons; to Sister Lord, my out-patient sister, for invaluable help; to my wife, Dr S. Girardin, for help in compiling this paper, and to Dr Steyn, Superintendent of the Frere Hospital, East London, South Africa, for permission to photograph and publish records of patients.

\section{REFERENCES}

Blumenthal, C. J. (1950). S. Afr. med. F. 24, 191.

Blumenthal, C. J. (1954). S. Afr. med. $\mathcal{F} . \mathbf{2 8}, 967$.

\section{EXPLANATION OF PLATE}

$a$. A very rare example of an unusually large spontaneous iris prolapse in an African male 9 years old. On section this prolapse was covered by a continuous layer of unbroken corneal epithelium.

b. A very rare example of triple spontaneous iris prolapse in an African girl i 6 years old. A recent organizing prolapse at Io o'clock and two healed old prolapses at 3 o'clock and 6 o'clock can be seen. Note triangular pupil.

\section{Protein and myopia}

\section{By P. A. Gardiner (Research Fellow in Ophthalmology), Guy's Hospital, London, S.E.I}

Acquired myopia is a disease which usually begins between the ages of 7 and II, but virtually always before physical growth stops. Deterioration in vision occurs in most children once myopia has begun, again until growth stops. The rate of deterioration is strongly associated with the rate of physical growth, those who grow fast and irregularly whether in weight or height deteriorate faster during these periods than those who grow slowly and more regularly. The situation in the eye, put simply, is that in the higher degrees of myopia the eyeball is always longer antero-posteriorly than a normal eye. In the lower degrees there is no association with the size of the eye. The condition is often optically due to increased curvature of the cornea relative 